\title{
L2 Motivational Self-System and Self-Efficacy: A Quantitative Survey- Based Study
}

\author{
Javad Roshandel \\ Imam Reza International University, Mashhad, Iran \\ Behzad Ghonsooly \\ Ferdowsi University of Mashhad, Iran
}

Afsaneh Ghanizadeh

Imam Reza International University, Mashhad, Iran,a.ghanizadeh@imamreza.ac.ir

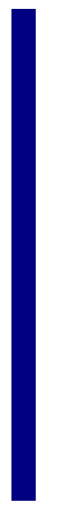

\begin{abstract}
The present study explored English as a foreign language (EFL) students' motivation and self-efficacy. This is accomplished by incorporating the ten subfactors of L2 motivational self-system namely; criterion measures, ideal L2 self, ought-to L2 self, family influence, instrumentality promotion, instrumentality prevention, attitudes towards learning English, attitudes towards L2 community, cultural interest, and integrativeness. The Persian version of L2 Motivational Selfsystem Questionnaire and the English version of Learners' Self- Efficacy Survey were used to collect the data. The results estimated via correlation and regression analyses revealed that there was a significant relationship between L2 motivation and L2 self-efficacy. In other words, all the ten sub-factors predicted L2 selfefficacy positively and significantly among which criterion measures, attitudes towards learning English, instrumentality promotion, and ideal L2 self were the most powerful predictors of L2 self-efficacy.
\end{abstract}

Keywords: EFL learners, students' motivation, motivation, self-efficacy, foreign language, quantitative survey

\section{INTRODUCTION}

From early on, the notion of motivation has been used to explain different types of behavior (e.g., drives connected to survival and basic biological needs). On the other hand, behavior is inspired by the desire or need to reach particular goals (e.g., avoidance of punishment, recognition, and promotion). Consequently, motivation as a theoretical construct is used to explain a process which initiates, guides, and maintains goal oriented treatments by directing and energizing the behavior towards achieving a particular outcome (Sansone \& Harackiewicz, 2000). The term motivation can also be used to describe the forces acting on or within individuals to direct behavior and explain diversities in the intensity of a particular action in which more intense behavior is the result of higher levels of motivation (Gibson, Ivancevich, \& Donnelly, 2000). In other

Citation: Roshandel, J., Ghonsooly, B., \& Ghanizadeh, A. (2018). L2 Motivational Self-System and Self-Efficacy: A Quantitative Survey-Based Study. International Journal of Instruction, 11(1), 329344. https://doi.org/10.12973/iji.2018.11123a 
words, motivation is intentional and directional. It is intentional since it refers to the persistence of actions and personal choices. It is also directional which implies that there is a driving force to attain a specific goal (Nel, Gerber, Van Dyk, Haasbroek, Schultz, Sono, \& Werner, 2001). In line with these conceptualizations, motivation as a key contributor to L2 mastering is believed to encompass all other factors involved in L2 learning (Ghanizadeh \& Rostami, 2015). Motivation thus embodies causes of people's actions, desires, and needs. According to Dörnyei (2001), motivation is a highly complex and multifaceted issue shaping one of the most crucial human characteristics. In other words, motivation is the changing arousal in an individual that instigates, terminates, and evaluates the cognitive processes in which primary desires and wishes can be prioritized and acted out.

Self-efficacy as another factor pertained to the present research can be defined as individuals' beliefs about their capabilities to produce designated levels of performance that exercise influence over events that affect their lives (Bandura, 1994). Bandura (1986) believes people's beliefs about their efficacy can be developed by four main sources of influence. It is widely accepted among educationalists that learners' beliefs and perceptions have a decisive role in creating learning environments that encourage them to become motivated learners, and to be persistent in their efforts to reach their personal achievement potential (Dweck, 2000). So it is reasonable to assume that learners' feelings influence the whole process of learning and in turn is shaped by their motivational disposition.

The pivotal objective of the present study is to delve into Dornyei's L2 motivational self-system in relation to self-efficacy to probe how these motivational factors interact.

\section{REVIEW OF THE RELATED LITERATURE}

In 2005, Zoltán Dörnyei, Professor of Psycholinguistics at the University of Nottingham, outlined the basis of a new approach to conceptualize L2 learning motivation within a "self" framework - the L2 Motivational Self System. As Dörnyei and Ushioda (2011) noted, this theoretical model was proposed "as a comprehensive synthesis of past research on the main dimensions of language learning motivation" ( $p$. 79 ) and "as a natural progression from Gardner's theory" (p. 80). The L2 Motivational Self System represents a major reformation of the previous motivational thinking, and its introduction marks the beginning of a new era in L2 motivation research, the sociodynamic period. The new term has been recognized by many as the most promising framework to move L2 motivation research forward (Csizér \& Kormos, 2009; MacIntyre et al., 2009; Ortega, 2009; Taguchi et al., 2009).

As Dörnyei and Ushioda (2011) pointed out, during the latter decades of the 20th century and the first decade of this century, with globalization, the fall of communism, and widespread political and economic migration, the world traversed by L2 learners has changed dramatically. In response to this changing global reality, L2 motivation is currently undergoing the process of being radically re-conceptualized and re-theorized in the context of contemporary notions of self and identity. Specifically, the L2 Motivational Self System has grown out of the combined effects of two significant 
theoretical developments, one taking place in the L2 field, the other in mainstream psychology. The growing dissatisfaction with the integrative motivation and major developments in psychological research on self helped the new model come into being (Dörnyei, 2009).

Dörnyei and other L2 motivation researchers (Csizér \& Kormos, 2009; Taguchi et al., 2009) believe that the concept of possible selves (Markus \& Nurius, 1986) offers the most promising way forward if L2 motivation research intends to move beyond integrativeness. Dörnyei (2005) explained that data obtained from a large-scale motivation survey were the trigger for his proposal of the L2 self-system. In 1993, 1999, and 2004, Dörnyei and Csizér conducted a repeated stratified national L2 learning attitude/motivation survey, which involved over 13,000 teenage L2 learners of English, German, French, Italian, and Russian in Hungary. It was the largest L2 motivation study ever, and its findings were detailed in a book entitled Motivation, language attitudes and globalization: A Hungarian perspective (Dörnyei, Csizér, \& Németh, 2006). As Taguchi et al. (2009) noted, one of the main findings of the study was that integrativeness was the most important component of the L2 motivation construct in the sense that, as demonstrated by Dörnyei and Csizér (2006), it "explained almost as much of the variance of the criterion measures as all the motivation components together" ( $p$. 453). Although the power of integrativeness was supported by Gardner's (1985) work, it did not make sense that it would have such an impact in a foreign language context like Hungary in which there was practically no English speaking community which English learners could join. The potency of integrativeness in a country without a salient L2 group certainly remains an enigma... (p. 67).

As mentioned above, major theoretical developments that took place in psychological research of the self enabled the re-conceptualization and re-theorization of the integrative concept from the perspective of self and identity. The formulation of Dörnyei's (2005) L2 Motivational Self System owes much to Higgins' (1987) SelfDiscrepancy Theory which is one of his most notable contributions to the psychological research on self and identity. Higgins (1989) described Self-Discrepancy Theory as "a general theory relating different patterns of self-beliefs to different kinds of emotional motivational predispositions" (p.129).

Within this theoretical framework, the analysis of the self starts from the recognition of its three basic domains; namely, the actual self, the ideal self, and the ought self. As Higgins (1987) explained:

There are three basic domains of the self: (a) the actual self, which is your representation of the attributes that someone (yourself or another) believes you actually possess; (b) the ideal self, which is your representation of the attributes that someone (yourself or another) would like you, ideally, to possess (i.e., a representation of someone's hopes, aspirations, or wishes for you); and (c) the ought self, which is your representation of the attributes that someone (yourself or another) believes you should or ought to possess (i.e., a representation of someone's sense of your duty, obligations, or responsibilities). (pp. 320-321) 
Self-discrepancies comprised inconsistencies between individuals' self-concept and pertinent self-guides. For example, a woman might experience a conflict between her own desires to become a successful professional and some other people's beliefs that she ought to be a housewife and mother. Such discrepancies produce discomfort in the individual, which may motivate the person to minimize discrepancies in order to alleviate the discomfort (Higgins, 1987). Therefore, motivation oftentimes comes as a result of someone's wish to reduce the discrepancy between one's actual self and one's ideal self, that is, one's image of what one would like to become. Motivation also comes about from the intention to lessen the gap between one's actual self and one's ought self, that is, one's perception of what one ought to become and what one's significant others would like one to become (Csizér \& Kormos, 2009). Higgins (1998) further pointed out that the ideal self-guides have a promotion focus that is associated with positive emotional-motivational predispositions like hopes, aspirations, and growth, whereas the ought self-guides have a prevention focus that is related to avoidance of negative outcomes that may result from one's failures to carry out duties or to meet one's own or others' expectations.

Dörnyei (2005) applied the core concepts and ideas of the Self-Discrepancy Theory, and proposed the L2 Motivational Self System. As Dörnyei (2005) explained, this system is made up of the following components:

1. Ideal L2 self, which is the L2-specific facet of one's "ideal self": if the person we would like to become speaks an L2, the "ideal L2 self" is a powerful motivator to learn the L2 because of the desire to reduce the discrepancy between our actual and ideal selves. Traditional integrative and internalized instrumental motives would typically belong to this component.

2. Ought-to L2 self, which concerns the attributes that one believes one ought to possess to meet expectations and to avoid possible negative outcomes. This dimension corresponds to Higgins' ought self and thus to the more extrinsic (i.e., less internalized) types of instrumental motives.

3. L2 learning experience, which concerns situated, "executive" motives related to the immediate learning environment and experience (e.g., the impact of the teacher, the curriculum, the peer group, the experience of success). (p. 29)

The first two theoretical components, the ideal L2 self and the ought-to L2 self are derived directly from Higgins' (1987) conceptualization of the ideal self and the ought self. The third component, the L2 learning experience, however, is conceptualized at a different level from the two self-guides. This bottom-up process is added to "represent the potential influence of the students' learning environment" (Dörnyei \& Ushioda, 2011 , p. 86) and is a reflection of the achievements of motivational studies in the 1990s, which recognized the significant impact of factors like the teacher, the curriculum, and peer group on L2 learners' motivation. As Dörnyei and Ushioda (2011) summarized the L2 Motivational Self System exclaims that there are three primary sources of the motivation to learn a foreign/second language - the learner's vision of oneself as an effective L2 speaker, the social pressure coming from the learner's environment, and positive learning experiences (p. 86). 
Many studies have been carried out in order to find the associations between student motivation and some other student-related variables. Gardner and Lambert (1972) were among the researchers who examined the relationship between motivation and attitude of L2 learners and concluded that the two constructs have a significant association related to each other. In another study Dornyei (1998) identified seven broad dimensions of motivation: (1) affective/integrative variables, (2) instrumental/pragmatic variables, (3) macrocontext related variables, (4) self-concept related variables, (5) goalrelated variables, (6) educational concept related variables, and (7) significant others related variables. He also addressed the significant work of others in relation to L2 motivation (e.g., Julkunen, 1989; Dornyei, 1994a; Schumann, 1998, as cited in Jahedizadeh, Ghanizadeh, \& Ghonsooly, 2016). Dornyei (1994b) also suggested that language learning can be organized systematically (on a continuum from intrinsic to extrinsic). Therefore, extrinsic factors influence motivation and anxiety. Consequently, it is likely that the foreign language instructor (as an external variable) will influence the learner's progression through stages of learning development. As a result, there is a significant association between the students' motivation to learn the languages and the teachers' teaching style (Dornyei, 1994). For instance, if a learner has a reflective learning style and a teacher has an impulsive teaching style, these preferences do not result in a positive response and influence student motivation, since the teacher expects an immediate response from a student who must first think and then provide an answer. This behavior may not be positively rewarded by a teacher with a contrasting learning style who prefers a more immediate response. This type of negative response could negatively influence the motivation for this type of learner (Ehrman, 2002).

In a similar vein, Lambert's views of additive and subtractive bilingualism (Lambert, 1981) suggested that transitional ESL programs have subtractive consequences due to the external desire of the students to learn the majority language, while native speakers of this majority language may choose to learn other languages and their attempts will result in additive consequences (Lambert, 1981). In other words, there are always additive characteristics when a member of a majority language group learns foreign languages, since they are able to learn the languages at no cost to their native language. In contrast, there are subtractive consequences for members of a minority language group learning another language which may be replaced their native language. Thus, the additive consequence results in increased motivation to lean the languages, since it is a kind of option which positively affects motivation to learn the language.

According to the Expectancy Value Theory (Wigfield \& Eccles, 2000), the greater the likelihood of success, achievement and perceived value in an activity, the more motivated the learners would be to complete the activity. Consequently, when the activity is done successfully, motivation and expectancy beliefs will be increased and higher achievement in the language will be achieved. Thus lower levels of anxiety would serve to further increase motivational risk taking behaviours and overall success in language learning.

Understanding the sources of motivation to learn the language is also of primary interest. Oxford (1996) suggested that finding the source of foreign language learner's 
motivation is essential, since individual motivation affects the L2 learning process. In addition to the source of motivation, understanding the ways to motivate language learners is important especially when the intrinsic motivation is low. According to Gardner's model, motivation consists of three main components: (a) motivational intensity, (b) the desire to learn the language, and (c) attitudes towards learning the language each of which has a great impact on student motivation. Furthermore, different motivational theories suggest that various types of motivation affect the learning process differently (Gardner \& Lambert, 1972).

More recently, Rostami, Ghanizadeh, and Ghonsooly (2015), conducted a study to examine the role of teacher burnout and family influence as two external factors in student motivation. In particular, four factors were considered in this study: (a) criterion measures which examine student intended efforts towards learning the language, (b) instrumentality-promotion that measures the regulation of personal goals, (c) attitudes to learning which assess situation-specific motives, and (d) family influence which examines parental roles regarding learning the language. The findings of this study demonstrated that there are significant interrelationships among the variables in which teacher burnout and family influence have significant impacts on student demotivation.

It is also necessary to take the needs of the learners into account. As Maslow (1970) stated, there are five basic needs: physiological, safety and security, needs of belonging, self-esteem, and self -actualization. If these basic needs are met for foreign language learners, anxiety will be decreased and motivation will be increased. But if these needs are not met, language learners may regress in their needs, performance, and motivation (Hosseini, Ghonsooly, \& Ghanizadeh, 2017) and the increased anxiety will affect motivation. Therefore, a negative cycle prevents successful foreign language learning. Students then are unlikely to advance to higher stages of learning and their intrinsic motivation to learn more foreign languages is significantly decreased.

Although motivation is a primary variable which affects language learning, other factors also play a significant role in language learning which are related to student motivation as well. Understanding the influence of anxiety on motivation and the foreign language learning process, for example, is equally important. Early empirical studies have been attempts to establish such a relationship (e.g., Lambert, 1981; Gardner \& Lalonede, 1985; Oxford, 1996; Dornyei, 1994a; 1998; 2000; 2001; 2005; MacIntyre,1995; 2001; Csiszr \& Dornyei, 2005). These studies suggest that students with higher level of intrinsic motivation to learn a language would have a high level of self-esteem and risk taking behaviors and are more open to change, tolerant of ambiguities and willing to employ different learning strategies to increase their success.

Other motivation-related studies are the attempts to show the relationship between motivation and metacognitive strategy use which often accounts for the difference between novice and expert learners (e.g., Boekaerts, Pintrich \& Zeidner, 2000; Rivers, 2001).

The major theoretical shift within the field of L2 motivation research from the traditional conceptualization of motivation by Gardner (1985) in terms of an 
integrative/instrumental dichotomy to the recent conceptualization of motivation by the Dörnyei's L2 Motivational Self System theory (2005) lead many motivational studies to use Dörnyei's model as a comprehensive framework.

In the past several years, quite a few quantitative studies and some qualitative investigations have been conducted to specifically test and validate Dörnyei's (2005) L2 Motivational Self System. All of these studies have provided confirmation of the proposed self-system (e.g., Csizér \& Kormos, 2009; Taguchi Magid, \& Papi, 2009; Ryan, 2009; Lamb, 2009; Ghanizadeh \& Rostami, 2015).

Self-efficacy as another factor pertained to the present study can be defined as individuals' beliefs about their capabilities to produce designated levels of performance that exercise influence over events that affect their lives (Bandura, 1994). Bandura (1986) believes that people's beliefs about their efficacy can be developed by four main sources of influence. The most effective way of creating a strong sense of efficacy is through mastery experiences. Successful performance in the past instils more confidence and positive perceptions of the self into people, and, thus, they expect successful performance in the future. Vicarious experiences provided by social models and significant others also help create and strengthen self-efficacy beliefs. Seeing people similar to oneself succeed by sustained effort raises observers' beliefs that they similarly possess the capabilities to master comparable activities required to succeed. Social persuasion is another way through which people's efficacy beliefs are formed and strengthened. People who are persuaded verbally that they possess the capabilities to master given skills and fulfill certain activities are likely to mobilize greater effort and sustain it while negative feedback from others makes them harbor self-doubts and dwell on personal deficiencies when problems arise. Finally, Bandura (1994) has argued that physiological and emotional states affect the ways in which efficacy beliefs are formed. These states can be positive, such as happiness and excitement, or negative, like stress, tension, and anxiety.

Due to the growing need for teaching and learning of English as an international language which holds many functions, the need for providing a condition for better learning and teaching become very important. For enhancing learning process, the knowledge of development psychology is required. The effort of understanding how motivational components are related is not only crucial for exploring student selfefficacy but also fundamental for understanding learners' achievement and success. This paper explores the interplay between EFL learners' motivation and self-efficacy from L2 motivational self-system perspective among Iranian EFL learners. The present study thus seeks to put forward a number of pertinent recommendations to enhance learner's emotional, cognitive, motivational, and psychological patterns conducive to language achievement.

\section{Purpose of the study}

The main purpose of this study is to investigate the role of EFL learners' motivation (measured via ten sub-factors of L2 motivational self-system) in their L2 self-efficacy. Viewed from a broader perspective, it seeks to examine and interpret the hypothesized relationships among two motivation-related factors within a single framework. The 
Dörnyei's L2 Motivational Self System measuring ten factors was employed to inform the present research. The factors are as follows:

1) Criterion measures which assess the learners' intended efforts towards learning English.

2) Ideal L2 self which refers to the "L2-specific facet of one's ideal self" (Dörnyei, 2005, p. 106).

3) Ought-to L2 self which measures "the attributes that one believes one ought to possess (i.e. various duties, obligations, or responsibilities) in order to avoid possible negative outcomes" (Dörnyei, 2005, p. 106).

4) Family influence which examines active and passive parental roles.

5) Instrumentality-promotion that measures the regulation of personal goals to become successful such as attaining high proficiency in English in order to make more money or find a better job.

6) Instrumentality-prevention which measures the regulation of duties and obligations such as studying English in order to pass an examination.

7) Attitudes to learning English that explores situation-specific motives related to the immediate learning environment and experience.

8) Attitudes to L2 community which investigates the learner's attitudes toward the community of the target language.

9) Cultural interest that measures the learner's interest in the cultural products of the L2 culture, such as TV, magazines, music and movies.

10) Integrativeness which measures attitude toward the second language, its culture and the native speakers of that language.

The role of each factor in L2 self-efficacy will be investigated. The present study will also aim at examining the predictive power of each motivational sub-factor in L2 selfefficacy and finding the most powerful predictor/s of self-efficacy. The following research questions are posed and investigated in this study:

Q1. What is the profile of EFL learners' L2 motivational self-system?

Q2. Is there any significant relationship between EFL learners' L2 motivation and their L2 self-efficacy?

Q3. Among the sub-factors of L2 motivational self-system which one is the most powerful predictor of L2 self-efficacy?

\section{METHOD}

\section{Participants}

The participants of the present study comprised 210 EFL students selected according to a convenience sampling among EFL learners studying English in language institutes and universities in Mashhad, a city in Iran. Convenience sampling was used in the present study because the researchers were teaching in language institutes and universities; so, the participants were selected because of their convenient accessibility and proximity to the researchers and based on a volunteering basis. 
The profile of the students is as follows: Out of 210 students 100 of them were studying English in language institutes and 110 participants were university students. Their age varied from 13 to 40 years old ( mean $=19$, standard deviation $=6.47$ ). Out of 210 students, 44 students held a diploma, 100 had a bachelor of arts (BA), 56 held a master of arts (MA), and 10 had Ph.D degree. Female participants' number was 114, while 96 were male.

\section{Instrumentation}

\section{L2 Motivational Self-system Questionnaire}

The current study employed an English learner questionnaire designed and validated by the School of English Studies of the University of Nottingham UK. The Persian version of the questionnaire translated and validated by Papi (2010) was utilized in the present study. This questionnaire is composed of two major parts: the first part consists of 76 items measuring the learners' attitudes and motivation concerning English learning ranging from "strongly disagree" to "strongly agree" and the second part consists of 10 questions about the learners' background information (e.g. gender, nationality, age, overseas experience, and self-rated English proficiency levels). The following table displays the reliability indices (measured via Cronbach's alpha) of the questionnaire in the original study (Papi, 2010).

Table 1

The reliability indices of the scale

\begin{tabular}{lll}
\hline Factor & Item No. & Reliability in original study \\
\hline Criterion measures & $8,16,24,32,40,50$ & 0.79 \\
\hline Ideal L2 self & $9,17,25,33,41,51$ & 0.79 \\
\hline Ought-to L2 self & $1,10,18,26,34,43$ & 0.75 \\
\hline Family influence & $2,11,19,27,35,44$ & 0.69 \\
\hline Instrumentality- promotion & $3,12,20,28,37,45$ & 0.67 \\
\hline Instrumentality-prevention & $4,13,29,36,42,48,53$ & 0.81 \\
\hline Attitudes to L2 L & $54,59,63,67,71,75$ & 0.82 \\
\hline Cultural interest & $57,61,65,74$ & 0.76 \\
\hline Attitudes to L2 culture & $58,62,66,70$ & 0.76 \\
\hline Integrativeness & $56,69,73$ & 0.56 \\
\hline
\end{tabular}

EFL Learners' Self- Efficacy Survey

To assess the EFL learners' level of self-efficacy, “Learners' Self- Efficacy Survey” will be used. This questionnaire was designed and standardized by Gahungu (2009). As Gahungu stated the questionnaire operationalizes the self-efficacy construct via scores obtained on 40 items ranging from never to always. To estimate the reliability of the "Self-Efficacy Survey", the Kurder-Richardson 21 reliability was computed and the result was .97 (Gahungu, 2009).

\section{Data Analysis}

To run the statistical analyses, SPSS version 22 was employed. To present descriptive statistics, means, minimums, maximums, and standard deviations of each factor and the 
corresponding sub-factors were computed. To examine the relationship between selfefficacy and motivational subcomponents, multiple correlations were utilized. To see what percentage of variability in self-efficacy can be accounted for by considering motivation, a regression analysis was run. Regression analysis contained three related analyses. In the first set of regression analysis, an ANOVA was run to see if the model containing self-efficacy and motivation. In this analysis, self-efficacy was considered as the dependent variable and motivation as the independent variable. In other words, the model sought to investigate the role of motivation in predicting self-efficacy. The second regression-associated analysis probed whether motivation is a positive predictor of selfefficacy. The third table computed the magnitude of the predictive power (in percentages) of motivation in accounting for self-efficacy.

\section{FINDINGS}

In response to the first research question probing the profile of Iranian EFL learners' motivation, descriptive statistics was utilized. Table 2 presents descriptive statistics of motivation and its sub-factors. Throughout this study, Criterion stands for criterion measures, Ideal stands for ideal L2 self, Ought for ought-to L2 self, Family for family influence, InsPro for Instrumentality-promotion, InsPre for instrumentality-prevention, ATLE for Attitudes to learning English, Culture for cultural interest, ATL2C for attitudes to L2 community, and Integrative for integrativeness. As the table indicates, InsPro receives the highest mean $(\mathrm{M}=36.78, \mathrm{SD}=2.92)$ followed by Ideal $(\mathrm{M}=33.26, \mathrm{SD}=2.43)$.

Table 2

Descriptive statistics of motivation and its sub-factors

\begin{tabular}{lccccc}
\hline & $\mathrm{N}$ & Minimum & Maximum & Mean & Std. Deviation \\
\hline Criterion & 210 & 14.00 & 36.00 & 31.93 & 2.81 \\
Ideal & 210 & 17.00 & 38.00 & 33.26 & 2.43 \\
Ought & 210 & 17.00 & 38.00 & 28.18 & 3.50 \\
Family & 210 & 25.00 & 38.00 & 32.88 & 2.30 \\
InsPre & 210 & 22.00 & 38.00 & 33.29 & 2.66 \\
Ins-pro & 210 & 27.00 & 42.00 & 36.78 & 2.92 \\
ATLE & 210 & 19.00 & 38.00 & 31.96 & 3.68 \\
Culture & 210 & 16.00 & 24.00 & 21.82 & 1.39 \\
ATL2C & 210 & 11.00 & 24.00 & 19.31 & 3.04 \\
Integrative & 210 & 9.00 & 19.00 & 16.48 & 1.56 \\
Total Motivation & 210 & 198.00 & 310.00 & 284.64 & 14.50
\end{tabular}

Table 3 shows descriptive statistics of self-efficacy.

Table 3

Descriptive statistics of self-efficacy

\begin{tabular}{llllll}
\hline & N & Minimum & Maximum & Mean & Std. Deviation \\
\hline Self-efficacy & 210 & 68.00 & 160.00 & 127.76 & 15.14 \\
\hline Valid N (listwise) & 210 & & & & \\
\hline
\end{tabular}

To address the relationship between EFL learners' L2 motivation and their L2 selfefficacy, correlational analysis was run the results of which are presented in Table 4. As 
can be seen, the correlations were observed to be significant between motivation subfactors and self-efficacy: Criterion $(r=0.37, p<0.05)$, Ideal $(r=0.34, p<0.05)$, Ought $(r=0.29, p<0.05)$, Family $(r=0.21, p<0.05)$, InsPre $(r=0.20, p<0.05)$, InsPro $(r=$ $0.35, p<0.05)$, ATLE $(r=0.36, p<0.05)$, Culture $(r=0.26, p<0.05)$, ATL2C $(r=$ $0.27, p<0.05)$, and Integrative $(r=0.19, p<0.05)$ among which Criterion, ATLE, InsPro, and Ideal displayed the highest correlations, respectively. This can be figured out by examining the magnitude of correlation coefficient designated by $r$. The asterisk in Table 4 is an indication of the presence of correlation. The closer the magnitude to 1 , the higher the correlation would be.

Table 4

The correlation coefficients among motivation, its sub-scales, and self-efficacy

\begin{tabular}{|c|c|c|c|c|c|c|c|c|c|c|c|c|}
\hline & 11 & 22 & 33 & 44 & 55 & 66 & 77 & 88 & 99 & 110 & 111 & 112 \\
\hline 1.Criterion & 01 & & & & & & & & & & & \\
\hline 2.Ideal &. $.37 * *$ & 11 & & & & & & & & & & \\
\hline 3.Ought &. $.35 * *$ &. $.22 * *$ & 11 & & & & & & & & & \\
\hline 4.Family &. $.20 * *$ &. $.25 * *$ &. .13 & 11 & & & & & & & & \\
\hline 5.Inspre &. $.26 * *$ &. $.33 * *$ &. .11 &. .08 & 11 & & & & & & & \\
\hline 6.InsPro & $.5 .8 * *$ &. $.32 * *$ &. .36 &. $.25^{*}$ &. $.21 * *$ & 11 & & & & & & \\
\hline 7.ATLE &. $.42 * *$ &. $.33 * *$ &. .43 &. $.29 *$ &. $.33 * *$ &. $.49 * *$ & 11 & & & & & \\
\hline 8.Culture & .0 .9 & $.2 .8 * *$ & .07 &. $.16^{*}$ &. .02 &. .11 & ..09 & 11 & & & & \\
\hline 9.ATL2C &. $.34 * *$ &. $.26 * *$ & .29 &. .13 &. $.26 * *$ &. $.40 * *$ &. $.30 *$ &. .06 & 11 & & & \\
\hline $\begin{array}{l}10 . \\
\text { Integrative }\end{array}$ &. .02 &. $.23 * *$ & ..08 &. .04 &. $.28 * *$ &. .08 &. $.19^{*}$ &. $.18^{* *}$ &. $.25 * *$ & 11 & & \\
\hline $\begin{array}{l}\text { 11.Self- } \\
\text { efficacy }\end{array}$ &. $.37 * *$ &. $.34 * *$ & .29 &. $.21 *$ &. $.20 * *$ &. $.35 * *$ &. $.36^{*}$ &. $.26 * *$ &. $.27 * *$ &. $.19 *$ & 11 & \\
\hline $\begin{array}{l}\text { 12.Motivati } \\
\text { on }\end{array}$ &. $.73 * *$ &. $.56 * *$ & ..62 &. $.35^{*}$ &. $.44 * *$ &. $.73 * *$ &. $.67 *$ &. $.23 * *$ &. $.64 * *$ &. $.26 *$ &. $.43^{*}$ & 11 \\
\hline
\end{tabular}

To investigate the predictive power of student motivation in accounting for their selfefficacy in response to the third research question, a stepwise regression analysis was employed. Table 5 is the ANOVA Table of regression. The magnitude of $F$-value and the amount of the respective $p$ value $(p<0.05)$ indicate the considered model is significant.

Table 5

The ANOVA table of regression

\begin{tabular}{llccccc}
\hline Model & & Sum of Squares & df & Mean Square & F & Sig. \\
\hline 1 & Regression & 9175.92 & 1 & 9175.92 & 49.21 & $.000^{\mathrm{b}}$ \\
& Residual & 38783.64 & 208 & 186.46 & & \\
& Total & 47959.56 & 209 & & & \\
\hline
\end{tabular}

b. Predictors: (Constant), Motivation

To analyze the data further, a regression analysis was conducted. Table 6 presents the results which indicate that student motivation is a positive predictor of the dependent variable (self-efficacy). 
Table 6

The results of regression analysis for motivation and self-efficacy

\begin{tabular}{|c|c|c|c|c|c|c|}
\hline \multirow{2}{*}{\multicolumn{2}{|c|}{ Model }} & \multicolumn{2}{|c|}{ Unstandardized Coefficients } & \multirow{2}{*}{$\begin{array}{c}\begin{array}{l}\text { Standardized } \\
\text { Coefficients }\end{array} \\
\text { Beta } \\
\end{array}$} & \multirow[b]{2}{*}{$\mathrm{t}$} & \multirow[b]{2}{*}{ Sig. } \\
\hline & & $\mathrm{B}$ & Std. Error & & & \\
\hline \multirow[t]{2}{*}{1} & (Constant) & 2.264 & 18.560 & & -.122 & .903 \\
\hline & Motivation & .457 & .065 & 437 & 7.015 & .000 \\
\hline
\end{tabular}

Table 7 illustrates the model summary statistics. The results reveal that the model containing the total scores of the motivation can predict self-efficacy to some degree. The $\mathrm{R}$ value is 0.43 , which indicates the correlation coefficient between motivation and self-efficacy. Its square value is 0.187 so it indicates that about $20 \%$ of the variation in self-efficacy can be explained by taking motivation into account.

Table 7

$\mathrm{R}$ square table for student motivation as the predictor of self-efficacy

\begin{tabular}{lcccc}
\hline Model & $\mathrm{R}$ & $\mathrm{R}$ Square & Adjusted R Square & Std. Error of the Estimate \\
\hline 1 & $.437^{\mathrm{a}}$ & .191 & .187 & 13.65503 \\
\hline a. Predictors: (Constant), Motivation & & &
\end{tabular}

\section{DISCUSSION}

The present study aimed at investigating the role of students' motivation in their selfefficacy from the L2 motivational self-system perspective. In effect, this study sought to find the effects of the ten sub-factors of L2 motivation on student self-efficacy. Concerning the first research question regarding profile of EFL learners' L2 motivational self-system the results indicated that all of the ten sub-factors of L2 motivation are significantly related to L2 self-efficacy. In other words, all aspects of L2 motivational self-system positively and significantly predicted student self-efficacy. This finding is in line with previous studies (e.g., Piniel \& Csizér, 2013). The distinguishing feature of the present study is that it utilized an L2 related scale (L2 motivational selfsystem) for measuring motivation, while in previous studies, general education motivational scales (such as Ryan, Pintrich, or Gardner) were employed.

The findings also demonstrated that among the sub-factors of L2 motivational selfsystem, criterion measures, attitudes towards learning English, instrumentality promotion, and ideal L2 self are the most powerful predictors of L2 self-efficacy, respectively. Taking the relationship between criterion measures and self-efficacy into account, the finding can be discussed according to the nature of this aspect of L2 motivational self-system. In other words, language choice and intended effort as the two dimensions of criterion measures are the motivating factors towards studying the L2. The significant correlation between criterion measures and efficacy is also consistent with previous findings (e.g., Dornyei, 2009). The second highest correlation was observed between attitudes towards learning English and L2 self-efficacy. In other words, if students perceive positive attitudes towards the process of language learning, they will feel more confident and self-efficient. 
The results of the present study also revealed that there was a significant relationship between instrumentality promotion and L2 self-efficacy. As Dornyie (2009) stated individuals naturally want to be professionally successful and consequently instrumental motives related to career enhancement are logically linked to the ideal L2 self. Moreover, there is a contrasting approach/avoid tendency among students in their future self-guides (Higgins, 1987) which in turn affects students' levels of self-efficacy. Concerning the relationship between ideal L2 self and self-efficacy, it was found that ideal L2 self positively and significantly predict student self-efficacy. The finding is in line with previous research. Michiko and Osamu (2012), for instance, found a strong association between the two constructs which confirm the claim made by Ushioda (2011), in which a closer link between self-efficacy and the ideal L2 self can be pointed out qualitatively. Indeed, the results of the present study generalize the findings of Michiko and Osamu (2012) on a quantitative basis using a survey and utilizing regression analysis.

\section{CONCLUSION}

Taken together, the findings of this study put forward the prospect of developing a multidimensional understanding of student motivation and its effect on L2 self-efficacy using the L2 motivational self-system which provides a comprehensive framework considering different aspects of L2 motivation. The findings highlighted the role of L2 motivation in giving rise to L2 self-efficacy. This finding in turn can have crucial implications for SLA research in general and EFL student learning in particular. It should, in the first place, inform both teachers and students of different aspects of L2 motivation and help them in ameliorating learning process. Teachers are responsible for identifying students' motivating factors and adapting methodologies, materials, and learning environment according to students' needs and preferences leading to students' confidence in their capabilities and self-fulfilment (Hosseini, Ghonsooly, \& Ghanizadeh, 2017).

The results of the present research have numerous implications for both students and teachers. Teachers should be aware of the most powerful motivating factors which lead to L2 self-efficacy towards EFL or ESL learning. Teachers can design interesting and challenging activities to motivate their students. Teachers are also recommended to consider student's attitudes, feelings, and values regarding EFL learning in order to exclude experiences of failure and lack of motivation (Ghanizadeh \& Royaei, 2015). Finally, by creating awareness in learners about the important role of these constructs in academic effectiveness, teachers can substantially improve their students' performance. Students can also learn about different aspects of L2 motivation and their impacts on their L2 self-efficacy and academic achievement.

\section{REFERENCES}

Bandura, A. (1986). Social foundations of thought and action: A social cognitive theory. Englewood Cliffs, NJ: Prentice-Hall.

Bandura, A. (1994). Self-efficacy. In V.S. Ramachaudran (Ed.), Encyclopedia of human Behavior (pp. 71-81). New York: Academic Press. 
Boekarts, M., Pintrich, P., \& Zeidner, M. (2000). Handbook of self-regulation. San Diego: Academic Press.

Csizer, K., \& Dornyei, Z. (2005). The internal structure of language learning motivation: Results of structural equation modeling. Modern Language Journal, 89(1), 19-36.

Csizér, K., \& Kormos, J., 2009. Learning experiences, selves, and motivated learning behaviour: A comparative analysis of structural models for Hungarian secondary and university learners of English, in: Dörnyei, Z., Ushioda E. (Eds.), Motivation, Language Identity and the L2 Self. Multilingual Matters, Bristol, pp. 98-119.

Dörnyei, Z. (2001). Teaching and researching motivation. Longman: Harlow.

Dörnyei, Z. (2005). The psychology of the language learner: Individual differences in second language acquisition. Mahwah, N. J.: Lawrence Erlbaum.

Dornyei, Z., \& Ushioda, E. (2011). Teaching and researching motivation (2nd ed.). Harlow, England: Pearson Longman.

Ehrman, M. (2002). Understanding the learner at the superior-distinguished threshold. In B. L. Leaver \& B. Shekhtman (Eds), Developing Professional language proficiency, Cambridge University Press, Cambridge.

Gahungu, O. (2009). Strategy use, self-efficacy, and language ability: Their relationship. Germany: Lambert Academic Publishing.

Gardner, R. C., \& Lambert, W. E. (1972). Attitudes and motivation in second languagelearning. Rowley, Massachusetts: Newbury House Publishers.

Hosseini, A. B., Ghonsooly, B., \& Ghanizadeh, A. (2017).

Pacific Edu Res (2017) 26: 171. doi:10.1007/s40299-017-0338-1

Ghanizadeh, A., \& Rostami, R. (2015). A Dörnyei-inspired study on second language motivation: A cross-comparison analysis in public and private contexts. Psychological Studies, 60(3), 292-301.

Ghanizadeh, A., \& Royaei, N. (2015). Emotional facet of language teaching: Emotion regulation and emotional labor strategies as predictors of teacher burnout. International Journal of Pedagogies and Learning, 10, 139-150.

Gibson, J. L., Ivancevich, J. M., \& Donnelly, J. H. (2000). Organizations: Behavior, structure, processes. Boston: McGraw-Hill.

Higgins, E. T. (1987). Self-discrepancy: A theory relating self and affect. Psychological Review, 94(3), 319-340.

Higgins, E. T. (1989). Self-discrepancy theory: What patterns of self-beliefs cause people to suffer? Advances in Experimental Social Psychology, 22, 93-136. 
Higgins, E. T. (1998). Promotion and prevention: Regulatory focus as a motivational principle. Advances in Experimental Social Psychology, 30, 1-46.

Jahedizadeh, S., Ghanizadeh, A., \& Ghonsooly, B. (2016). The role of EFL learners' demotivation, perceptions of classroom activities, and mastery goal in predicting their language achievement and burnout. Asian-Pacific Journal of Second and Foreign Language Education, 16(1), 1-17. DOI 10.1186/s40862-016-0021-8

Julkunen, K. (1989). Situation and task-specific motivation in foreign language learning and teaching. Joensuu: University of Joensuu.

Lamb, T.E. (2009). Controlling learning: relationships between motivation and learner autonomy. In R. Pemberton, S. Toogood, \& A. Barfield (Eds.), Maintaining control (pp. 67-86). Hong Kong: Hong Kong University Press.

Lambert, W. (1981). Bilingualism and language acquisition. In J. Winitz (Ed.). Native language and foreign language acquisition, New York Academy of Sciences, 9-22.

MacIntyre, P. (1995). How does anxiety affect second language learning? A reply to Sparks and Ganschow. The Modern Language Journal, 79, 90-99.

MacIntyre, P., Fram, S., Kushner, P. J., Bettex, N. D., O’brien, W. J., Hobbie, J. E., \& kling., G. W. (2009). Climate-related variations in mixing dynamics in an Alaskan arctic lake. Limnol. Oceanogr, 54, 2401-2417.

Markus, H. R., \& Nurius, P. (1986). Possible selves. American Psychologist, 41, 954969.

Michiko, U., \& Osamu, K. (2012). Validating the L2 motivational self system in a Japanese EFL context: The interplay of L2 motivation, L2 anxiety, self-efficacy, and the perceived amount of information. Language Education \& Technology, 49, 1-22.

Moos, D., \& Azevedo, R. (2006). The role of goal structure in undergraduates ${ }^{\text {ee }}$ use of self-regulatory processes in two hypermedia learning tasks. Journal of Educational Multimedia and Hypermedia, 15(1), 49-86.

Nel, P. S., Gerber, P. D., Van Dyk, P. S., Haasbroek, G. D., Schultz, H. B., Sono, T., \& Werner, A. (2001). Human resource management. (6 ${ }^{\text {th }}$ Ed.). Cape Town: Oxford Uuniversity Press.

Oxford, R. (1996). Language learning strategies around the world: Cross cultural perspectives. Second Language Teaching and Curriculum Center, University of Hawaii at Manoa. University of Hawaii Press.

Ortega, L. (2009). Understanding second language acquisition. London: Hodder Arnold.

Papi, M. (2010). The L2 motivational self-system, L2 anxiety, and motivated behavior: A structural equation modelling approach. System, 38, 467-479. 
Piniel, K., \& Csizér, K. (2013). L2 motivation, anxiety and self-efficacy: The interrelationship of individual variables in the secondary school context. Studies in Second Language Learning and Teaching, 3(4), 523-550.

Rivers, W. (2001). Autonomy at all costs: An Ethnography of metacognitive selfassessment and self-management among experienced language learners. The Modern Language Journal, 85, 27-290.

Rostami, S., Ghanizadeh, A., \& Ghonsooly, B. (2015). External factors affecting second language motivation: The role of teacher burnout and family influence. Iranian Journal of Applied Linguistics, 18(2), 165-187.

Ryan, R. (2009). Self-determination theory and wellbeing. Wellbeing in Developing Countries (WeD), 1, 23-30.

Sansone, C., \& Harackiewicz, J.M. (2000). Looking beyond rewards: The problem and promise of intrinsic motivation. In C. Sansone and J.M. Harackiewicz (Eds.), Intrinsic and Extrinsic Motivation: The Search for Optimal Motivation and Performance. San Diego, CA: Academic Press. Published.

Schumann, J. (1998). The neurobiology of affect in language. Oxford: Blackwell.

Taguchi, T., Magid, M., \& Papi, M. (2009). The L2 motivational self system among Japanese, Chinese, and Iranian learners of English: A comparative study. In Z. Dörnyei \& E. Ushioda (Eds.), Motivation, language identity and the L2 self (pp. 43-65). Clevedon, UK: Multilingual Matters.

Wigfield, A., \& Eccles, J. S. (2000). Expectancy-value theory of motivation. Contemporary Educational Psychology, 25, 68-81. 